\title{
Effectiveness of Teaching-Learning Strategies for Calculation Based Pharmacy Courses in a Bachelor's Program
}

\author{
Bazigha Kadhim Abdul Rasool ${ }^{1, \text { *, Sabeena Salam }}{ }^{2}$ \\ ${ }^{1}$ Department of Pharmaceutics, Dubai Pharmacy College, Dubai, UAE \\ ${ }^{2}$ Head of Institutional Effectiveness Unit, Dubai Pharmacy College, Dubai, UAE \\ Email address: \\ bazigha@dpc.edu (B. K. A. Rasool), sabeena@dpc.edu (S. Salam) \\ ${ }^{*}$ Corresponding author
}

\section{To cite this article:}

Bazigha Kadhim Abdul Rasool, Sabeena Salam. Effectiveness of Teaching-Learning Strategies for Calculation Based Pharmacy Courses in a Bachelor's Program. Science Journal of Education. Vol. 4, No. 2, 2016, pp. 108-112. doi: 10.11648/j.sjedu.20160402.24

Received: May 8, 2016; Accepted: May 17, 2016; Published: May 30, 2016

\begin{abstract}
The aim of this study was to select suitable teaching-learning strategies to improve students' performance in Calculation Based Pharmaceutical Courses (CBPCs). The criteria selected were a quantitative analysis of student performance during the course presentation, appropriateness of prerequisites and student feedback on the appropriateness of teaching tools. The study was carried out on first-year students of the undergraduate pharmacy program. The survey results proved that, teaching aids/techniques are extensively affecting students' performance, literacy and skills in calculation based educational environment. After implementing the planned teaching-learning strategies, most of the students were able to achieve the course level intended learning outcomes. This was evident through the analysis of their grade point average in the final examinations of CBPCs. Unquestionably, numerical literacy is considered as one of the prime competencies for pharmacists. Therefore, the effective methods of teaching for the course delivery and designing integrated course prerequisite were found significantly affecting students' performance and achievements in CBPCs.
\end{abstract}

Keywords: Pharmacy, Calculation, Teaching Aids, Dubai

\section{Introduction}

In pharmaceutical curricula, across the globe, quantitative literacy is a fundamental and critical element of program outcomes. Accordingly, some pharmacy schools deliver calculations content in a standalone calculations course while others include this content as a part of a broader course [1]. Ever since numerical reasoning began to play a crucial role in the pharmaceutical education as well, the teaching of calculations based subjects had been stressed upon in pharmacy schools. Hence, with the aim of generating competent pharmacist, it is an essential task for instructors to improve calculation skills in students [2]. In addition, it was reported in the literature that calculation mistakes in pharmacy practice such as dose calculation, drug compounding, and admixture do dramatically participate to suboptimal or even unsafe patient outcomes [3, 4].
Researchers in calculation based pharmaceutical education are becoming increasingly aware of implementing a variety of teaching methods that may ultimately improve students' numeracy skills $[5,6]$. Furthermore, the impact of technologybased learning tools on the effectiveness of class delivery in these courses was investigated by instructors [7, 8].

In the United Arab Emirates (UAE), no summary of evidence has been published about the effectiveness of pharmaceutical calculation courses in the undergraduate pharmacy programs. Therefore, the aim of this study was to select suitable mechanisms to improve students' performance in Calculation Based Pharmaceutical Courses (CBPCs) by determining the appropriateness of teaching tools and revising the syllabus contents of the Mathematic prerequisite course. 


\section{Methodology}

\subsection{Course Delivery}

Two CBPCs namely: Pharmaceutical Calculations and Physical Pharmacy are offered to first-year students during their second semester of the BPharm program at Dubai Pharmacy College for girls, Dubai, UAE. The prerequisite foundation course of CBPCs is Mathematics, which is given during the first semester of the same academic year. The methods of teaching in CBPCs include didactic lectures, classinteraction, problem-solving as class activities and homework. Students also were engaged in group work during the sessions. The teaching tools that are used to deliver the lecture are Interactive Smart Board (ISB), and Power Point Presentation (PPT). Both subjects were taught by the same instructor.

\subsection{Mechanisms to Improve Students' Performance}

In this study, the mechanisms to improve students' performance in CBPCs were performed through:

\subsubsection{Quantitative Analysis of Student Performance during the Course Presentation}

Analysis of students' grade distribution in "Physical Pharmacy and Pharmaceutical Calculation" for the midterm and final exams of the academic year 2014-15, was performed.

\subsubsection{Appropriateness of Prerequisites}

Quantitative analysis of students' performance in Mathematics offered in first semester of the same academic session, was conducted to evaluate the validity and reliability of the prerequisite course.

\subsubsection{Student Feedback on the Appropriateness of Teaching Tools in the CBPCs}

This study was approved by the Ethics and Research Committee, Dubai Pharmacy College, UAE. PPT was used before midterm exam while the ISB was introduced in the second half of the semester after the midterm exam. At the end of the courses, questionnaires were distributed to students to assess their overall perception of the teaching tools.

The survey was conducted through SurveyMonkey ${ }^{\circledR}$ online survey instrument. The questionnaire was available online for one week starting on July $6^{\text {th }}, 2015$. Out of 72 first year students, 68 respondents answered this survey.

\subsection{Data Analysis}

The data as students' percentage were collected, tabulated and analyzed statistically by one-way ANOVA test using GraphPad Prism (version 3.0). Significance was defined at $p$ values $<0.05$. All members of the research team contributed to developing the final interpretation.

\section{Results}

\subsection{Background of Participants}

Table 1 represents the demographic distribution of the surveyed students. The 68 respondents were all single females. The majority of the students $(92.6 \%)$ were between 15 and 20 years. A half of the students hold secondary education certificate from Ministry of Education in the UAE and one-fourth from other Arab countries. About 18\% of students are graduates of United Kingdom (UK) and United States (US) while 7\% from other boards. In secondary level Mathematics, $35 \%$ and $15 \%$ of students scored between 90 $100 \%$ from Ministry of Education (MOE)-UAE and other curricula, respectively (Fig. 1).

Table 1. Demographic distribution of the respondents.

\begin{tabular}{lll}
\hline \multirow{2}{*}{ Variable } & \multicolumn{2}{l}{ Response } \\
\cline { 2 - 3 } Age & No. of students & $\%$ \\
$15-20$ & 63 & 92.6 \\
$21-25$ & 5 & 7.4 \\
$>26$ & 0 & 0.0 \\
Marital status & & \\
Single & 68 & 100.0 \\
Married / Divorced & 0 & 0.0 \\
$*$ Secondary certificate & & \\
MOE (UAE) & 34 & 50.0 \\
MOE (Arabic) & 17 & 25.0 \\
IGCSE (UK) & 4 & 5.9 \\
IB (USA) & 8 & 11.8 \\
Others & 5 & 7.3 \\
\hline
\end{tabular}

*MOE: Ministry of Education; IGCE: International General Certificate of Secondary Education;

IB: International Baccalaureate; CBSE: Central Board of Secondary Education.

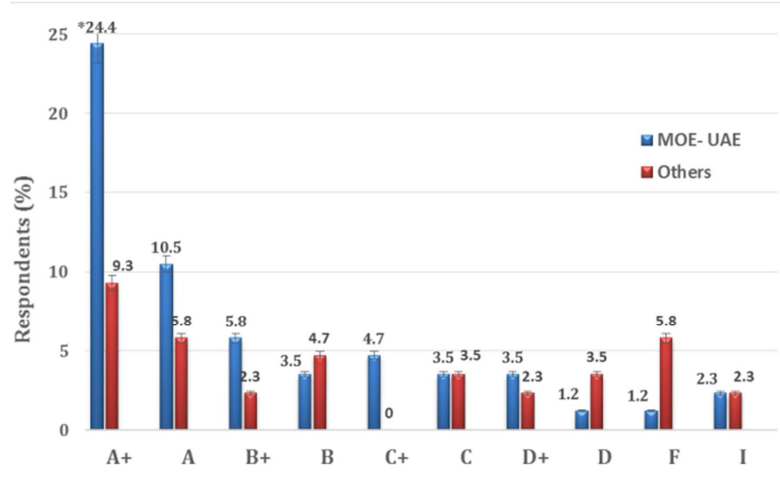

Figure 1. Students' grades distribution in Mathematics of MOE/UAE secondary certificate comparing to others.

\subsection{Grade Distribution: Midterm-Exam}

After the midterm exam, the instructor analyzed students' results in CBPCs. It was found that the results were unsatisfactory specifically in Physical Pharmacy, as shown in Table 2. More than half $(52.7 \%)$ of the class got disappointing results (grades $\mathrm{D}+, \mathrm{D}$ and I) in Physical Pharmacy while less than quarter $(20.7 \%)$ of the same class got unsatisfactory grades in Pharmaceutical Calculations. Legend for course grading system of Dubai Pharmacy College (DPC) is outlined in Table 3. Note that, the same instructor taught both subjects and the same methods and 
tools were used for teaching. In order to improve students' performance, the researchers probed firstly into students' perception survey on teaching tools and secondly prerequisite course evaluation.

Table 2. Grade distribution among students in physical pharmacy and pharmaceutical calculations in midterm and final examination.

\begin{tabular}{|c|c|c|c|c|c|c|c|c|c|c|c|}
\hline \multirow{2}{*}{ Course } & \multirow{2}{*}{ Exam } & \multicolumn{10}{|c|}{ Grades } \\
\hline & & $\mathbf{A}+$ & $\mathbf{A}$ & B+ & B & $\mathrm{C}+$ & $\mathrm{C}$ & D+ & D & $\mathbf{F}$ & I \\
\hline \multirow{2}{*}{ Physical Pharmacy } & Midterm & 12.5 & 9.7 & 5.6 & 6.9 & 6.9 & 4.2 & 6.9 & 19.4 & 26.4 & 1.4 \\
\hline & Final & *31.9 & 9.7 & 13.9 & 11.1 & 11.1 & 1.4 & 9.7 & 1.4 & 8.3 & 1.4 \\
\hline \multirow{2}{*}{ Pharm. Calculations } & Midterm & 34.7 & 15.3 & 8.3 & 9.7 & 5.6 & 5.6 & 6.9 & 6.9 & 6.9 & 0.0 \\
\hline & Final & 36.8 & 13.2 & 7.9 & 14.5 & 3.9 & 3.9 & 6.6 & 2.6 & 5.3 & 0.0 \\
\hline
\end{tabular}

* Significant results $(p<0.05)$. Data is given as percentage.

Table 3. Dubai Pharmacy College-legend for course grading system.

\begin{tabular}{lll}
\hline Range of Marks & Grade Symbol & Performance \\
\hline $95-100$ & $\mathrm{~A}+$ & Outstanding \\
$90-94.99$ & $\mathrm{~A}$ & Excellent \\
$85-89.99$ & $\mathrm{~B}+$ & Very Good \\
$80-84.99$ & $\mathrm{~B}$ & Good \\
$75-79.99$ & $\mathrm{C}+$ & Satisfactory \\
$70-74.99$ & $\mathrm{C}$ & Pass \\
$65-69.99$ & $\mathrm{D}+$ & Unsatisfactory \\
$60-64.99$ & $\mathrm{D}$ & Unsatisfactory \\
Below 65 & $\mathrm{~F}$ & Failed \\
& $\mathrm{I}$ & Incomplete \\
\hline
\end{tabular}

Table 4. Students' aptitude and perception of the teaching aids.

\begin{tabular}{|c|c|c|c|c|c|}
\hline \multirow[b]{2}{*}{ Questions } & \multicolumn{5}{|c|}{ Respondents (\%) } \\
\hline & *ISB & *PPT & Both & Others & $\begin{array}{l}\text { If you select others, } \\
\text { please specify }\end{array}$ \\
\hline $\begin{array}{l}\text { Q.1. Which teaching aid do you prefer for calculation based pharmacy } \\
\text { courses? }\end{array}$ & 39.7 & 5.9 & 42.6 & 11.8 & 11suggested use of Whiteboard \\
\hline Q.2.In which methods do you feel lost in the class. & 20.6 & 57.4 & 8.8 & 13.2 & 3suggested using none \\
\hline $\begin{array}{l}\text { Q.3. Which method do you think is better in preparing you (students) for } \\
\text { examination? }\end{array}$ & 39.7 & 19.1 & 35.3 & 5.9 & $\begin{array}{l}\text { 1suggested more practice on } \\
\text { problems solving activities }\end{array}$ \\
\hline Q.5. Which method do you think improves your skills in calculations? & 64.7 & 1.5 & 23.5 & 10.3 & 5 suggested use of Blackboard \\
\hline
\end{tabular}

*ISB: Interactive Smart Board and PPT: Power Point Presentation.

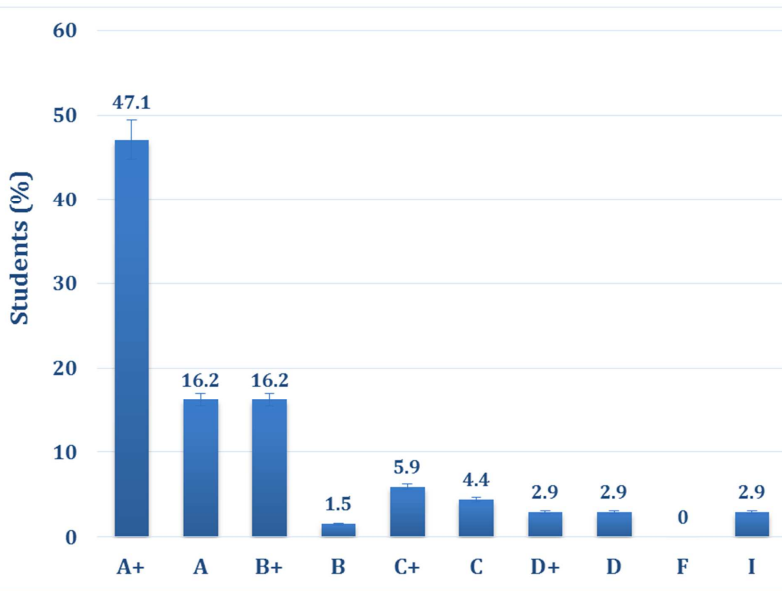

* Significant result $(\mathrm{p}<0.05)$.

Figure 2. Students' grades in Mathematics in the first academic session.

\subsection{Student Perception}

Subsequent to unsatisfactory performance in the midterm examination, we wanted to know learners perception to enhance their performance. The student participants in this study provided data, giving them an opportunity to voice their opinions on the nature of effective teaching for CBPCs. This approach proved successful as respondents offered rich descriptions and narratives about their classroom experiences. The emerging theme from the focused group discussions was mainly on technology-based teaching tools.

As illustrated in Table 4, 40\% of the surveyed students said they preferred ISB and almost $60 \%$ feel lost in class during PPT - only 6\% voted for PPT. When students were asked which method was better to prepare them for examination, it was observed that almost $40 \%$ said the ISB but 52 students suggested more low-stake quizzes and problem-solving activities. Towards preparing for more advanced courses, around $35 \%$ of students preferred ISB and interestingly two suggested implementing projects. Nevertheless, projects are introduced in the advanced study plan of BPharm program at Dubai Pharmacy College. On the way to improving calculation skills, $65 \%$ of the students believed that ISB is the more efficient teaching tool though few preferred conventional Blackboard. 


\subsection{Outcomes}

Based on the observations and findings, several improvements to teaching learning strategies were incorporated in CBPCs. The instructor decided to use ISB rather than PPT in both courses. In Physical Pharmacy, more in-class low-stake quizzes and problem-solving activities were conducted. Furthermore, remedial classes were offered to weak students who got grades less than $\mathrm{C}$ to improve their numerical skills.

The students were able to achieve the course level intended learning outcomes. This was evident through the analysis of their grade point average. In Physical Pharmacy, there was a significant $(p<0.05)$ improvement in student performance. Results revealed that more than $80 \%$ secured above satisfactory grades (Table 2) i.e. $30 \%$ of students who were at risk improved in the final exam. In Pharmaceutical Calculations, however, insignificant $(p>0.05)$ results were obtained, since only around $6 \%$ improvement in students' performance was achieved and 94\% secured above satisfactory grades (Table 2).

\subsection{Appropriateness of Prerequisite}

The majority of our students in the first year Pharmacy program typically have completed their undergraduate general Mathematics prior to proceeding into the full courses offered in CBPCs. When students showed unsatisfactory results in midterm exams in CBPCs, we decided to analyze grade distribution in Mathematics because at the beginning we believed that their unsatisfactory background in Mathematics could be the main reason behind this problem. Results showed that almost half of the students (47.1\%) scored $\mathrm{A}^{+}$(95-100 marks).

\section{Discussion}

We noticed that students' performance in CBPCs in the midterm exam was unsatisfactory. The percentage of the failures was high specifically in Physical Pharmacy. This may be due to the fact that, the weight of Physical Pharmacy (Three credit hour for theory and one credit hour for practical) is more than Pharmaceutical Calculation (Two credit hour for theory).

To improve pharmacy students' overall ability to perform fundamental and application-based calculations [9] and since we believe in the importance of developing numerical literacy as a vital skill required for addressing the type of job presentations that occur in today's pharmaceutical practice environment $[10,11]$, therefore, we discussed what factors possibly influence the students learning and performance.

The key indicators including course content, course organization, overall course evaluation, faculty evaluation, and practical evaluation (if applicable) were evaluated by the Quality Assurance office and the Program Review and Assessment Committee of the college.

For the purpose of this study, we considered analyzing students' grade distribution in the midterm exam in Physical
Pharmacy and Pharmaceutical Calculation as well as their performance in the prerequisite Mathematics course. We did not take into consideration practical results of the course. We compared only the components of written examination. Then, the perception of students on teaching tools was collected to decide the appropriate class delivery methods to prepare them to become competent pharmacists. Despite the fact that web-based technology played a significant role in the survey data gathering; initially, the researchers employed the openend nature of the data gathering. Even though the manual analysis of the data was tedious, therefore focused group discussions were conducted and the direct interaction with student responses proved rewarding.

After analyzing results, several teaching-learning plans for improvement were prepared [12]. The instructor decided to use ISB rather than PPT in classroom teaching according to students' preference. Most importantly, in Physical Pharmacy, more in-class low-stake quizzes and problemsolving activities were conducted. Additionally, tutorials were given to weak students. A common thread in the feedback is encapsulated in the following student's comment:

"For motivating the students, it is better if the PPT can be emailed to us so that we can practice it at home well in advance. We should have more quizzes and self - directed - learning to motivate us otherwise we will leave everything to study before the exam. I think it would be better if worksheets can be given and can be discussed in class".

After implementing the mentioned teaching-learning strategies, most of the students were able to achieve the course/s intended learning outcomes. This was evident through the analysis of their grade point average in the final examinations.

Unquestionably, teaching aid is not the only factor behind the low result. Therefore, we reviewed the prerequisite courses and their mathematical background from secondary school. Although the results showed that students admitted to the college had high scores in Mathematics (K 12) and desirable results in Mathematics (prerequisite course for the BPharm), but their performance in these CBPCs were unsatisfactory. Accordingly, we revisited the syllabus of the prerequisite Mathematics course. Substantive changes in the course content were recommended to integrate the requirements of the calculation-based courses, which were approved by Program Review and Assessment Committee.

This study is not without limitation. The effectiveness of changes implemented in the prerequisite course content is not yet evaluated.

\section{Conclusion}

Due to unsatisfactory performance of students in the midterm exam of CBPCs, the need to use appropriate class teaching mechanisms that suits the students' needs and improves their performance in numeracy, was investigated. According to students' perception, class-teaching aids were found to dramatically affect their understanding and learning 
in these courses. As well, advanced techniques as problemsolving activities and concept checking class interactions were imperative strategies to improve students' skills in calculation. Furthermore, revising and modifying the contents of the prerequisite course (Mathematics) was a crucial factor to bridge the gap of student learning.

\section{Acknowledgments}

We would like to express our sincere gratitude to the Prof. Saeed Ahmed Khan, Dean of Dubai Pharmacy College, for the continuous support of the related research and Mrs. Nabeerah Aftab, member IEU, for the technical support.

\section{Competing Interests}

The authors declare that they have no competing interests.

\section{References}

[1] Brown, M. C. \& Hanggi, A. (2007). Pharmaceutical calculations instruction and assessment in US colleges and schools of pharmacy. American Journal of Pharmaceutical Education, 1(5), 1-6. PMCID: PMC2064885.

[2] Brown, M. C. (2003). Introduction to pharmaceutical calculations. American Journal of Pharmaceutical Education, 67(2), 1-8. doi: 10.5688/aj670267.

[3] Herout, P. M. \& Erstad, B. L. (2004). Medication errors involving continuously infused medications in a surgical intensive care unit. Critical Care Medicine, 32(2): 428-32. PMID: 14758159.

[4] Oldridge, G. J., Gray, K. M., McDermott, L. M. \& Kirkpatrick, C. M. J. (2004). Pilot study to determine the ability of health-care professionals to undertake drug dose calculations. International Medical Journal, 34(6), 316-9. PMID: 15228392.
[5] Lust, E., Vuchetich, P. \& Monaghan, M. (2002). Effectiveness of pharmacy calculation education via the internet: A comparison between campus-based and web-based student performance. American Association of Colleges of Pharmacy Annual Meeting, 103(Jul), 33.

[6] O'Sullivan, T. A. (1998). Comparison of pharmacy calculations taught by traditional lecture vs self-study. American Association of Colleges of Pharmacy Annual Meeting, 99(Jul), 98.

[7] Ramanathan, M. (1999). Use of multiplatform CD-ROMs for disseminating supplementary learning materials in a pharmaceutical calculations course. American Journal of Pharmaceutical Education, 63(3), 333-38. doi: aj630314.

[8] Delafuente, J. C., Araujo, O. E. \& Legg, S. M. (1998). Traditional lecture format compared to computer-assisted instruction of pharmacy calculations. American Journal of Pharmaceutical Education, 62, 62-66. doi: 10.1.1.135.8710.

[9] Michael A. H., Shauna M. B. \& Elizabeth P (2013). Impact of a required pharmaceutical calculations course on mathematics ability and knowledge retention. Am J Pharm Educ., 77(6): 124. doi: 10.5688/ajpe776124.

[10] Rolfe, S. \& Harper, N. J. (1995). Ability of hospital doctors to calculate drug doses. British Medical Journal, 310(6988), 1173-1174. PMCID: PMC2549558.

[11] Wood, S., Hanoch, Y., Barnes, A., Liu, P. J., Cummings, J., Bhattacharya, C. \& Rice, T. (2011). Numeracy and Medicare Part D: The importance of choice and literacy for numbers in optimizing decision making for Medicare's prescription drug program. Psychology and Aging, 26(2), 295-307.

[12] Teachers Education Programs and Online Learning Tools: Innovations in Teacher Preparation (2013). Hartshorne, R., Heafner, T. L. \& Petty, T. M., IGI Global, USA, p. 224. 